\title{
Anti-inflammatory activity of Syzygium aromaticum (L.) Merrill \& Perry oil in carrageenan-induced paw edema in female rats
}

\author{
Brijesh R. Humbal, Kamlesh A. Sadariya , Jaimin A. Prajapati, Shailesh K. Bhavsar and Aswin M. Thaker \\ Department of Veterinary Pharmacology and Toxicology, College of Veterinary Science and Animal Husbandry, \\ Anand Agricultural University, Anand-388001, Gujarat, India
}

Received September 13, 2019: Revised October 30, 2019: Accepted November 5, 2019: Published online December 30, 2019

\begin{abstract}
The present study was planned to evaluate in vivo anti-inflammatory activity of Syzygium aromaticum (L.) Merrill \& Perry oil (clove oil), following single dose oral administration @ 100, 250 and $500 \mathrm{mg} / \mathrm{kg}$ in female wistar rats by using carrageenan-induced paw edema model. Twenty five rats were divided randomly into 5 groups and each group consists of five female rats. All rats were injected subcutaneously with $0.1 \mathrm{ml}$ of $10 \% \mathrm{w} / \mathrm{v}$ carrageenan suspension subcutaneously as a local acute edema inducer after 30 min subsequent to oral administration of clove oil. Rats of control groups were kept untreated. Rats of standard control group were treated orally with indomethacin@10 mg/ $\mathrm{kg}$ body weight as a reference standard drug. Rats of other three treatment groups were treated with clove oil @ 100, 250 and $500 \mathrm{mg} / \mathrm{kg}$ body weight, respectively. Edema was expressed as the increase in paw volume in $\mathrm{ml}$ and measured up to the tibiotarsal articulation. Volume of edematous paw was measured at $0 \mathrm{~h}$ (before treatment), 1, 2, 3, 4, 6 and $24 \mathrm{~h}$ after treatments. Increase in paw thickness was measured by using digital plethysmometer and per cent inhibition was calculated. The anti-inflammatory effect of clove oil was highest at $3 \mathrm{~h}(35.46 \%)$ at the dose of $500 \mathrm{mg} / \mathrm{kg}$. The anti-inflammatory effect of standard drug indomethacin (42.99\%) was higher than clove oil at $3 \mathrm{~h}$. Clove oil at $3 \mathrm{~h}$ all doses gave higher anti-inflammatory effect. Clove oil showed dose dependent anti-inflammatory activity in female wistar rats.
\end{abstract}

Key words: Syzygium aromaticum (L.) Merrill \& Perry, clove oil, anti-inflammatory, paw edema

\section{Introduction}

Plant essential oils possess various applications mainly in health, agriculture, cosmetic and food industries. Use of essential oils in traditional systems of medicine is being practiced since ancient time. Essential oils also called volatile or ethereal oil are aromatic oily liquid, obtained from different plant materials (flowers, buds, seeds, leaves, twigs, bark, wood, fruits and roots). Essential oils are complex mixtures of low molecular weight (usually less than 500 daltons) compounds extracted by steam distillation, hydrodistillation or solvent extraction procedures (Nakatsu et al., 2000). Researchers from all over the world are trying to characterize a range of biological properties of essential oils which includes antimicrobial, antiviral, antimutagenic, anticancer, antioxidant, antiinflammatory, immunomodulatory and antiprotozoal activities (Bakkali et al., 2008).

Plants of the genus Eugenia (Syzygium), comprising of about 100 species, grow in tropical climate, in which Syzygium aromaticum

Author for correspondence: Dr. Kamlesh A. Sadariya Assistant Professor, Department of Veterinary Pharmacology and Toxicology, College of Veterinary Science and Animal Husbandry, Anand Agricultural University, Anand-388001, Gujarat, India

E-mail: dr kasadariya@yahoo.co.in

Tel.: +91-9427180817

Fax: $+91-2692-261486$

Copyright (c) 2019 Ukaaz Publications. All rights reserved.

Email: ukaaz@yahoo.com; Website: www.ukaazpublications.com
(L.) Merrill \& Perry or Eugenia caryophyllata Thun. plant is a high (up to $15 \mathrm{~m}$ ), evergreen tree of the family-Myrtaceae (Gora, 2005). It is commonly called clove in English, laung in Hindi and laving in Gujarati. The clove is an aromatic, dry, fully grown, but unopened flower bud of clove tree. Clove is a tree which is growing in islands of Indonesia, Tanzania, Sri Lanka, Madagascar, India and Malaysia (Arung et al., 2011). In India, clove is mostly grown in the hilly tracts of Tamilnadu, Karnataka and Kerala states. Clove relieves stomach pain, nausea and vomition (Bhowmik et al., 2012). Clove has a deodorizing property and so used in perfumes and cosmetics (Daniel et al., 2009). Eugenol, a key compound found in clove is an excellent agent for prevention of metastasis related to oxidative stress (Nam, 2012).

Clove oil can be obtained from distillation of buds, leaf or stem, each resulting in oil having different characteristics. Clove bud oil is a colourless or yellow liquid. Clove buds contain 15 to $20 \%$ of oil by weight. The main oil constituents are eugenol (70-95\%), eugenol acetate (up to $20 \%$ ) and $\beta$-caryophyllene (12-17\%) (Guenther, 1950). Various activities of clove oil like an anti-inflammatory, analgesic, antiseptic, deworming, disinfectants and antibacterials because it inhibits the growth or kills most pathogens have been were reported (Nowak et al., 2012). The clove oil nanoemulsion is a potential source of natural antibacterial agents and to be used as food preservatives (Shahvi, 2016). The essential oil of clove has biocidal activity against Aedes albopictus (tiger mosquitos), thereby 
helping in the control of malaria (Bhat and Kempraj, 2009). Stress which is very common in every individual can also be relieved with the help of hydro-alcoholic extracts of clove oil (Singh et al., 2009). Clove oil is also used for the treatment of sore throat, colds, catarrh and inflammation of the mucous membranes of the mouth. It also helps to deal with breathing problems, general weakness and neuralgia (Cimanga et al., 2002). Clove and its essential oil has been found effective in poultry to improve growth performance, control some intestinal pathogens and stimulate digestion and also showed strong antimicrobial, antifungal, anti-inflammatory, anesthetic, anticarcinogenic, anti-parasitic and antioxidant activities (Mitsch et al., 2004; Najafi and Torki, 2010). The alcoholic extract of clove buds showed significant antibacterial activity against Propionibacterium acnes and Staphylococcus epidermis (Singh et al., 2018). The clove oil and cinnamon oil showed promising in vitro antibacterial activity against both gram-positive (Staphylococcus aureus, Listeria monocytogenes and Streptococcus agalactiae) and gram-negative (Salmonella typhimurium and Escherichia coli) bacteria (Prajapati et al., 2018). Recently reported studies revealed promising antiinflammatory effects of essential oils, i.e., cinnamon oil showed anti-inflammatory effect in carrageenan-induced edema model in male and female wistar rats (Prajapati et al., 2019a; Prajapati et al., $2019 \mathrm{~b}$ ) and also similar study reported for clove oil in male wistar rats (Humbal et al., 2019). There are limited reports on the antiinflammatory activity of clove oil. Hence, the present study was done to evaluate an anti-inflammatory activity of clove oil in carrageenan-induced paw edema in rats.

\section{Materials and Methods}

\subsection{Experimental animals}

The study was conducted on adult healthy female wistar rats. Twenty five female rats (220 to $250 \mathrm{~g}$ ) of 8-10 weeks of age were procured from Cadila Healthcare Ltd., Ahmedabad, Gujarat. The experimental protocol was approved by Institutional Animal Ethics Committee (Project No. IAEC/279/VPT/2018) of College of Veterinary Science and Animal Husbandry, Anand, Gujarat and protocols were followed according to the guidelines of committee for the purpose of control and supervision of experiments on animals (CPCSEA). The animals were housed in standard polypropylene cages and maintained under controlled room temperature $\left(22 \pm 2^{\circ} \mathrm{C}\right)$ and relative humidity $(55 \pm$ $5 \%$ ) with $12 \mathrm{~h}$ light and $12 \mathrm{~h}$ dark cycle. All the rats were fed normal pellet diet (mention name of company) and deionized water was provided ad libitum throughout the study period. All the rats were kept under acclimatization for 5 days prior to grouping and initiation of the experiment. All necessary managemental procedures were adopted to keep the rats free from stress.

\subsection{Drugs and chemicals}

Clove essential oil (Natural, Functional grade) and carrageenan (Nongelling, mixture of $\lambda \& \kappa$ carrageenan) were purchased from SigmaAldrich, India. Indomethacin was purchased from local medical store of Anand district (Gujarat).

\subsection{Preparation of carrageenan and indomethacin solution}

For the preparation of $10 \% \mathrm{w} / \mathrm{v}$ carrageenan suspension, $0.5 \mathrm{~g}$ carrageenan was dissolved in $5 \mathrm{ml}$ of normal saline. For the preparation of Indomethacin suspension, each $25 \mathrm{mg}$ capsule was dissolved in $5 \mathrm{ml}$ of distilled water to get the concentration of $5 \mathrm{mg} / \mathrm{ml}$.

\subsection{Induction of paw edema in rats}

The in vivo anti-inflammatory assay was carried out using rat paw edema method as described by Winter et al. (1962). Rats were injected subcutaneously with $0.1 \mathrm{ml}$ of $10 \% \mathrm{w} / \mathrm{v}$ carrageenan suspension $(0.1 \mathrm{ml}$ of a $1 \%$ suspension in $10 \%$ saline $)$ in the subplanter region of the left hind limb as a local acute edema inducer after $30 \mathrm{~min}$ of oral administration of clove oil as well as indomethacin in respective groups as mentioned below.

\subsection{Experimental design}

All the rats were divided randomly in to 5 groups, having 5 rats in each group. Rats of control group (C1) were kept without ant treatment. Rats of standard control group (C2) were treated with single dose of indomethacin $(10 \mathrm{mg} / \mathrm{kg}$, orally). The rats of each treatment group (T1, T2, T3) were treated with clove oil at the dose of 100,250 and $500 \mathrm{mg} / \mathrm{kg}$ b.wt. orally, respectively.

\subsection{Measuring of paw edema volume}

Inflammation in the form of edema was expressed as the increase in paw volume $(\mathrm{ml})$. The paw volume was measured up to the tibiotarsal articulation using plethysmometer (PLM-01 plus, Orchid Scintific Instrument, India) at $0 \mathrm{~h}$ (before treatment), 1, 2, 3, 4, 6 and $24 \mathrm{~h}$ after treatments.

\subsection{Percent inhibition of inflammation}

Percent inhibition of paw edema volume in wistar rats was calculated using formula as $(\%)$ Inhibition $=[$ Mean paw volume (control)Mean paw volume (treated)]/Mean paw volume (control)

\subsection{Statistical analysis}

All the data have been presented as mean \pm SE. Statistical comparison of the mean values in different groups was made using one-way analysis of variance (ANOVA), using software SPSS (Version 25). Significant differences $(p<0.05)$ between different experimental groups were determined by Duncan's test.

\section{Results}

The present study was conducted to evaluate in vivo antiinflammatory activity of clove oil @ 100, 250 and $500 \mathrm{mg} / \mathrm{kg}$ body weight in female wistar rats. During the study period, no clinical signs of toxicity were observed in rats upon oral administration of clove oil. In the present study, peak inflammation was observed between 3-4 h after subcutaneous injection of carrageenan suspension $(0.1 \mathrm{ml}$ of a $1 \%$ suspension in $10 \%$ saline $)$ in the subplanter region of the left hind limb.

The result of anti-inflammatory effect is presented as change in paw volume in Table 1 and also graphically depicted in Figure 1 and percentage values of inhibition of inflammation by different treatments are presented in (Table 2 and graphically depicted in Figure 2). The results revealed that clove oil showed antiinflammatory effect with all three doses. The anti-inflammatory effect of indomethacin was highest at $3 \mathrm{~h}(42.99 \%)$ as compared to 
other doses of clove oil. The anti-inflammatory effect of clove oil was highest at $3 \mathrm{~h}(35.46 \%)$ at the dose of $500 \mathrm{mg} / \mathrm{kg}$. The antiinflammatory activity of clove oil was found dose dependent in this experiment. In our study, the significant decrease in paw edema

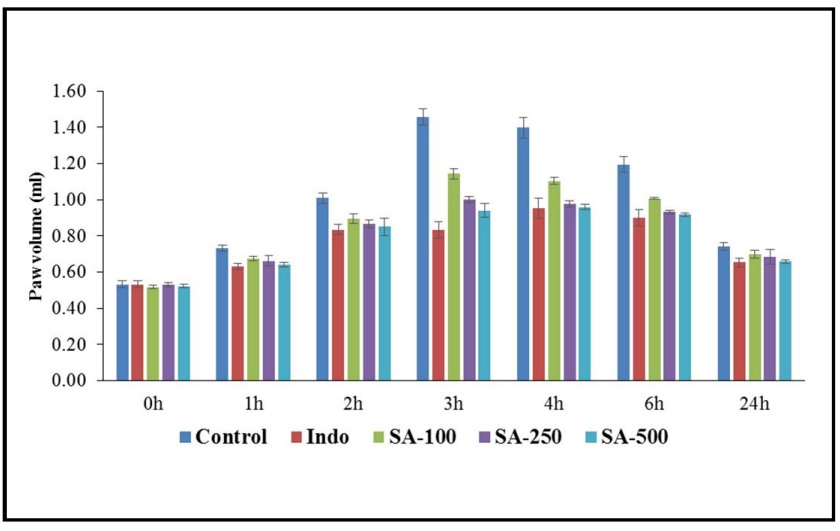

Figure 1: Effect of oral administration of clove oil on carrageenaninduced rat paw edema $(\mathrm{ml})$ in female wistar rats. volume was observed in carrageenan-induced inflammation in wistar rats treated with indomethacin $(10 \mathrm{mg} / \mathrm{kg})$ and clove oil @ 100, 250 and $500 \mathrm{mg} / \mathrm{kg}$ b.wt. Clove oil showed dose dependent antiinflammatory activity.

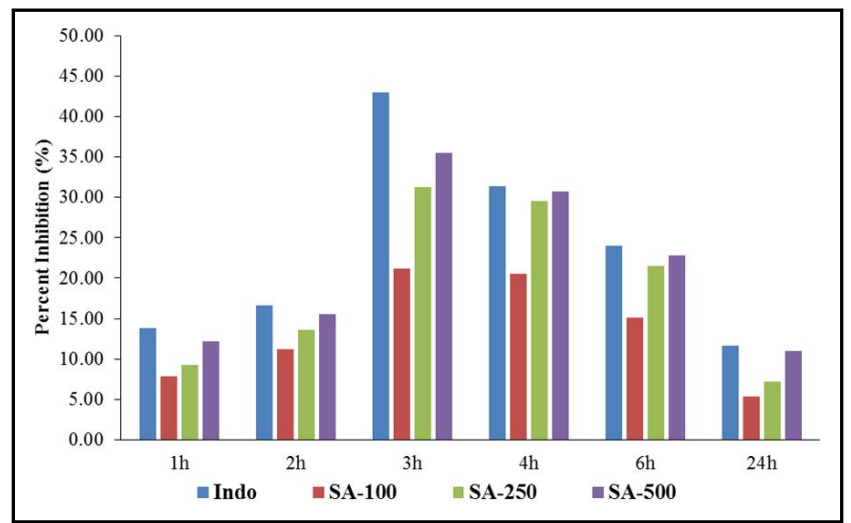

Figure 2: Percent inhibition of inflammation in wistar female rats under different treatments.

Table 1: Effect of oral administration of clove oil on carrageenan-induced paw edema (ml) in female wistar rats $($ Mean $\pm \mathrm{SE}$, $\mathrm{n}=5)$

\begin{tabular}{|c|c|c|c|c|c|c|c|}
\hline Group & $0 \mathrm{~h}$ & $1 \mathrm{~h}$ & $2 \mathrm{~h}$ & $3 \mathrm{~h}$ & $4 \mathrm{~h}$ & $6 \mathrm{~h}$ & $24 \mathrm{~h}$ \\
\hline Control(C1) & $0.53 \pm 0.02$ & $0.73 \pm 0.02^{b}$ & $1.01 \pm 0.03^{b}$ & $1.46 \pm 0.05^{\mathrm{d}}$ & $1.4 \pm 0.06^{\mathrm{c}}$ & $1.19 \pm 0.04^{\mathrm{c}}$ & $0.74 \pm 0.02^{\mathrm{b}}$ \\
\hline Indo(C2) & $0.53 \pm 0.02$ & $0.63 \pm 0.02^{a}$ & $0.84 \pm 0.03^{a}$ & $0.83 \pm 0.05^{a}$ & $0.95 \pm 0.06^{\mathrm{a}}$ & $0.90 \pm 0.04^{\mathrm{a}}$ & $0.65 \pm 0.02^{\mathrm{a}}$ \\
\hline SA-100(T 1$)$ & $0.52 \pm 0.01$ & $0.67 \pm 0.01^{\mathrm{a}}$ & $0.90 \pm 0.03^{\mathrm{a}}$ & $1.14 \pm 0.03^{\mathrm{c}}$ & $1.10 \pm 0.02^{\mathrm{b}}$ & $1.01 \pm 0.01^{\mathrm{b}}$ & $0.70 \pm 0.02^{\mathrm{ab}}$ \\
\hline $\mathrm{SA}-250$ (T2) & $0.53 \pm 0.01$ & $0.66 \pm 0.03^{a}$ & $0.87 \pm 0.02^{\mathrm{a}}$ & $1.00 \pm 0.02^{b}$ & $0.98 \pm 0.02^{\mathrm{a}}$ & $0.93 \pm 0.01^{\mathrm{a}}$ & $0.69 \pm 0.04^{\mathrm{ab}}$ \\
\hline SA-500(T3) & $0.52 \pm 0.01$ & $0.64 \pm 0.01^{\mathrm{a}}$ & $0.85 \pm 0.05^{\mathrm{a}}$ & $0.94 \pm 0.04^{b}$ & $0.96 \pm 0.02^{\mathrm{a}}$ & $0.92 \pm 0.01^{\mathrm{a}}$ & $0.66 \pm 0.01^{\mathrm{a}}$ \\
\hline
\end{tabular}

Mean value with dissimilar superscript in a column vary significantly at $p<0.05$.

Indo=Indomethacin @ $10 \mathrm{mg} / \mathrm{kg}$ b.wt in wistar rats

SA-100 = Syzygium aromaticum @ $100 \mathrm{mg} / \mathrm{kg}$ b.wt

SA-250=Syzygium aromaticum @250 mg/kg b.wt

SA-500=Syzygium aromaticum @ $500 \mathrm{mg} / \mathrm{kg}$ b.wt

Table 2: Percent inhibition of inflammation in wistar female rats under different treatments

\begin{tabular}{|c|c|c|c|c|c|c|}
\hline Group & $1 \mathrm{~h}$ & $2 \mathrm{~h}$ & $3 \mathrm{~h}$ & $4 \mathrm{~h}$ & $6 \mathrm{~h}$ & $24 \mathrm{~h}$ \\
\hline Indo & 13.78 & 16.67 & 42.99 & 31.41 & 24.00 & 11.66 \\
\hline SA-100 & 7.85 & 11.16 & 21.16 & 20.52 & 15.10 & 5.35 \\
\hline SA-250 & 9.23 & 13.61 & 31.22 & 29.50 & 21.53 & 7.18 \\
\hline SA- 500 & 12.20 & 15.52 & 35.46 & 30.76 & 22.81 & 10.95 \\
\hline
\end{tabular}

Indo=Indomethacin @ $10 \mathrm{mg} / \mathrm{kg}$ b.wt in wistar rats SA-100=Syzygium aromaticum@100 mg/kg b.wt SA-250=Syzygium aromaticum@250 mg/kg b.wt SA-500=Syzygium aromaticum@500 mg/kg b.wt

\section{Discussion}

Similar to the present study, many researcher were utilised this carrageenan-induced paw oedema model in rats to evaluate in vivo anti-inflammatory activity in rats. Reported studied on the in vivo anti-inflammatory effect of ethanolic stem bark extract of Cordia africana was carried out using carrageenan-induced paw edema model in rats (Tijjani et al., 2015), Similarly, Sridevi et al. (2017) also reported topical anti-inflammatory activity of an herbal gel containing solanesol extracted from tobacco scrap using carrageenan induced paw edema model in albino wistar rats. Likewise, recently the anti-inflammatory activity of rutin $(100 \mathrm{mg} / \mathrm{kg})$ and meloxicam $(5 \mathrm{mg} / \mathrm{kg})$ following its intramuscular administration was also assessed using carrageenan-induced paw edema model in rats (Modi et al., 2019).

In support to our findings, similar observations were reported for the anti-inflammatory activity of Eugenia caryophyllata oil at 0.025 , $0.050,0.100$ and $0.200 \mathrm{ml} / \mathrm{kg}$ body weight in carrageenan-induced paw edema in rats revealed $46.55,90.15,66.94$ and $82.78 \%$ inhibition 
of inflammation, respectively (Ozturk and Ozbek, 2005). Likewise, anti-inflammatory activity of ethanolic extract of $S$. aromaticum flower bud in wistar rats at 50,100 and $200 \mathrm{mg} / \mathrm{kg}$ body weight were reported with 42,45 and $52 \%$ inhibition of inflammation at $5 \mathrm{~h}$ post administration (Tanko et al., 2008). Similar results were also reported for eugenol oil by inflammatory exudates volume in carrageenan-induced paw edema in rats at 100, 200 and $400 \mathrm{mg} / \mathrm{kg}$ body weight and result revealed that the oral administration of eugenol significantly inhibited paw edema by $22.2,40$ and $41.1 \%$ at 2-4 $\mathrm{h}$ after carrageenan injection and the inhibition rate was comparable to that of indomethacin (Daniel et al., 2009). Rodrigues et al. (2009) investigated the in vivo effect of water-soluble part of hydro-alcoholic extract of clove on pro-inflammatory cytokines (IL-1 beta and IL-6) production by macrophages in BALB/c mice. Results showed that the treatment of mice with water extract of clove was found to inhibit macrophages to produce both IL-1 beta and IL-6 which suggest an anti-inflammatory action of hydroalcoholic extract of clove. Likewise, Grespan et al. (2012) reported the efficacy of eugenol, a compound obtained from the essential oil of cloves (S. aromaticum) in collagen-induced arthritis. Treatment with eugenol starting at the onset of arthritis (day 25) ameliorated these clinical signs of collagen-induced arthritis. Anti-inflammatory activity of the aqueous extract of $S$. aromaticum in acute inflammation at $1 \mathrm{~g} / \mathrm{kg}$ body weight in carrageenan induce paw edema model in rats has been reported with $84 \%$ inhibition of paw edema as compare to control at $3 \mathrm{~h}$ (Ahmad et al., 2012). Antiinflammatory activity of clove oil was studied in mice at a dose of $33 \mathrm{mg} / \mathrm{kg}$ body weight intraperitoneal in which clove oil significantly suppressed the increase paw thickness by $50.6 \%$ compared with control mice at $3 \mathrm{~h}$ (Taher et al., 2015). Similarly, anti-inflammatory effect of ethanolic extract of $S$. aromaticum in carrageenan-induced paw edema in rats has been reported with significant decrease in the edema at efficacy rates of $79.41,82.39$ and $63.92 \%$ at the dose of $500 \mathrm{mg} / \mathrm{kg}$ body weight at $2^{\text {nd }}, 4^{\text {th }}$ and $6^{\text {th }} \mathrm{h}$, respectively (Saeed et al., 2017). Nikoui et al. (2017) studied the anti-inflammatory effect of clove oil in thirty adult male dogs which were divided into four groups after surgical incision on abdomen. They reported that in the clove oil $(25 \mathrm{mg} / \mathrm{kg})$ treated animals, there was significant decrease in edema as compared to control dogs. Singh et al. (2018) evaluated anti-inflammatory effect of the clove bud oil $(100,200$, 400,800 and $1000 \mu \mathrm{g} / \mathrm{ml}$ ) and they observed dose-dependent antiinflammatory response with increasing concentration of the clove bud oil. However, the essential oil (1\%, v/v) exhibited significant effect comparable results to that of diclofenac taken as reference standard. In support to our study, the anti-inflammatory effect of clove oil was highest at $3 \mathrm{~h}(35.77 \%)$ at the dose of $500 \mathrm{mg} / \mathrm{kg}$ in carrageenan-induced paw edema in male wistar rats and it showed dose dependent anti-inflammatory effect at various doses (Humbal et al., 2019). In another reported studies on essential oil, following single dose oral administration $(50,100$ and $200 \mathrm{mg} / \mathrm{kg})$ of cinnamon oil (C. zeylanicum) showed significant dose dependent antiinflammatory activity in male and female wistar rats were reported (Prajapati et al., 2019a; Prajapati et al., 2019b).

\section{Conclusion}

The present study revealed that oral administration of clove oil showed dose dependent anti-inflammatory activity @ 100, 250 and $500 \mathrm{mg} / \mathrm{kg}$ body weight in female wistar rats. Rat paw edema model was successfully developed by injecting subcutaneously $0.1 \mathrm{ml}$ of $10 \% \mathrm{w} / \mathrm{v}$ carrageenan suspension $(0.1 \mathrm{ml}$ of a $1 \%$ suspension in $10 \%$ saline) in the sub-planter region of the left hind limb.

The anti-inflammatory effect of indomethacin was higher as compare all three doses of clove oil treated rats. The highest antiinflammatory activity of all three doses of clove oil was observed at $3 \mathrm{~h}$ post oral administration in female wistar rats. However, further studies are required to elucidate the mechanism behind this anti-inflammatory effect.

\section{Acknowledgements}

Authors are thankful to the Dean/Principal, College of Veterinary Science and Animal Husbandry, Anand Agricultural University, Anand for the financial support and infrastructure facilities to carry out the research work.

\section{Conflict of interest}

The authors declare that there are no conflicts of interest in the course of conducting the research. All the authors had final decision regarding the manuscript and decision to submit the findings for publication.

\section{References}

Ahmad, T.; Shinkafi, T. S.; Routray, I.; Mahmood, A. and Ali, S. (2012). Aqueous extract of dried flower buds of Syzygium aromaticum inhibits inflammation and oxidative stress. J. Basic. Clin. Pharm., 3(3):323.

Arung, E. T.; Matsubara, E.; Kusuma, I. W.; Sukaton, E.; Shimizu, K. and Kondo, R. (2011). Inhibitory components from the buds of clove (Syzygium aromaticum) on melanin formation in B16 melanoma cells. Fitoterapia, 82(2):198-202.

Bakkali, F.; Averbeck, S.; Averbeck, D. and Idaomar, M. (2008). Biological effects of essential oils: A review. Food Chem. Toxicol., 46(2):446-475.

Bhat, S. K. and Kempraj, V. (2009). Biocidal potential of clove oils against Aedes albopictus: A comparative study. Afr. J. Biotechnol., 8(24): 6933-6937.

Bhowmik, D.; Kumar, K. S.; Yadav, A.; Srivastava, S.; Paswan, S. and Dutta, A. S. (2012). Recent trends in Indian traditional herbs Syzygium aromaticum and its health benefits. J. Pharmacogn. Phytochem., 1(1): $13-23$

Cimanga, K.; Kambu, K.; Tona, L.; Apers, S.; De Bruyne, T.; Hermans, N. and Vlietinck, A. J. (2002). Correlation between chemical composition and antibacterial activity of essential oils of some aromatic medicinal plants growing in the Democratic Republic of Congo. J. Ethnopharmacol., 79(2):213-220.

Daniel, A. N.; Sartoretto, S. M.; Schmidt, G.; Caparroz-Assef, S. M.; BersaniAmado, C. A. and Cuman, R. K. N. (2009). Anti-inflammatory and antinociceptive activities of eugenol essential oil in experimental animal models. Rev. Bras. Farmacogn., 19(1B):212-217.

Gora, J. and Lis, A. (2005). The most valuable essential oils. Torun: Publisher of the Nicolaus Copernicus University. 
Grespan, R.; Paludo, M.; de Paula Lemos, H.; Barbosa, C. P.; Bersani-Amado, C. A.; de Oliveira Dalalio, M. M. and Cuman, R. K. N. (2012). Anti-arthritic effect of eugenol on collagen-induced arthritis experimental model. Biol. Pharm. Bull., 35(10):1818-1820.

Guenther, E. (1950). The essential oils, Volume 4, Van Nostrand, New York, pp:396-437.

Humbal, B.R.; Sadariya, K.A.; Prajapati, J.A.; Bhavsar, S.K. and Thaker, A.M. (2019). Evaluation of in vivo anti-inflammatory activity of Syzygium aromaticum oil in male wistar rats. Pharma Innovation., 8(7):540-543

Mitsch, P.; Zitterl-Eglseer, K.; Kohler, B.; Gabler, C.; Losa, R. and Zimpernik, I. (2004). The effect of two different blends of essential oil components on the proliferation of Clostridium perfringens in the intestines of broiler chickens. Poult. Sci., 83(4):669-675.

Modi, F. D.; Bhavsar, S. K.; Patel, J. H.; Varia, R. D.; Modi, L. C.;Modi, M. and Kale, N. (2019). Pharmacokinetic profile of rutin after intramuscular administration in rats favoursits in vivo anti-inflammatory activity in carrageenan-induced rodent model of inflammation. Ann. Phytomed., 8(1):185-192.

Najafi, P. and Torki, M. (2010). Performance, blood metabolites and immunocompetaence of broiler. J. Anim. Vet. Adv., 9(7):1164-1168.

Nakatsu, T.; Lupo Jr. A. T.; Chinn Jr., J. W. and Kang, R. K. (2000). Biologica activity of essential oils and their constituents. Studies in Natural Products Chemistry, 21:571-631.

Nam, H. and Kim, M. M. (2013). Eugenol with antioxidant activity inhibit MMP-9 related to metastasis in human fibrosarcoma cells. Food. Chem. Toxicol., 55:106-112.

Nikoui, V.; Ostadhadi, S.; Bakhtiarian, A.; Abbasi-Goujani, E.; HabibianDehkordi, S.; Rezaei-Roshan, M. and Giorgi, M. (2017). The antiinflammatory and antipyretic effects of clove oil in healthy dogs after surgery. Pharma Nutrition, 5(2):52-57.

Nowak, K.; Ogonowski, J.; Jaworska, M. and Grzesik, K. (2012). Clove oilproperties and applications. Chemik, 66(2):145-152.

OztUrk, A. and Ozbek, H. (2005). The anti-inflammatory activity of Eugenia caryophyllata essential oil: An animal model of antiinflammatory activity. Eur. J. Gen. Med., 2(4):159-163.

Prajapati, J.A.; Humbal, B.R.; Sadariya, K.A.; Bhavsar, S.K. and Thaker, A.M. (2019a). Experimental evaluation of anti-inflammatory activity of Cinnamomum zeylanicum oil in male wistar rats. J. Pharmacogn. Phytochem., 8(4):2483-2486.
Prajapati, J.A.; Humbal, B.R.; Sadariya, K.A.; Bhavsar, S.K. and Thaker, A.M. (2019b). Determination of in vivo anti-inflammatory potential of Cinnamomum zeylanicum oil in female wistar rats. Pharma Innovation, 8(7):544-547.

Prajapati, J.A.; Humbal, B.R.; Sadariya, K.A.; Bhavsar S.K. and Thaker A.M. (2018). In vitro antibacterial sensitivity of cinnamon and clove oils against gram-positive and gram-negative bacteria. J. Vet. Pharmacol. Toxicol., 17(1):63-67.

Rodrigues, T. G.; Fernandes Jr, A.; Sousa, J. P. B.; Bastos, J. K. andSforcin, J. M. (2009). In vitro and in vivo effects of clove on pro-inflammatory cytokines production by macrophages. Nat. Prod. Res., 23(4): 319-326.

Saeed, T. A.; Osman, O. A.; Amin, A. E. and El Badwi, S. M. (2017). Safety assessment and potential anti-inflammatory effect of ethanolic extract of Syzygium aromaticum in Albino Rats. Adv. Biosci. Biotechnol., 8(11):411.

Shahavi, M. H.; Hosseini, M.; Jahanshahi, M.; Meyer, R. L. and Darzi, G. N. (2016). Clove oil nanoemulsion as an effective antibacterial agent: Taguchi optimization method. Desalin. Water Treat., 57(39):18379-18390.

Singh, A. K.; Dhamanigi, S. S. and Asad, M. (2009). Anti-stress activity of hydro-alcoholic extract of Eugenia caryophyllus buds (clove). Indian J. Pharmacol., 41(1):28.

Singh, V.; Pahuja, C.; Ali, M. and Sultana, S. (2018). Analysis and bioactivities of essential oil of the flower buds of Syzygium aromaticum (L.) Merrill \& Perry. J. Med. Plants, 6(6):79-83.

Sridevi, P.; Vijayanand, P. and Raju, M. B. (2017). Formulation and evaluation of anti-inflammatory herbal gel containing isolated solanesol. Ann. Phytomed., 6(1):127-131.

Taher, Y. A.; Samud, A. M.; El-Taher, F. E.; ben-Hussin, G.; Elmezogi, J. S.; AlMehdawi, B. F. and Salem, H. A. (2015). Experimental evaluation of anti-inflammatory, antinociceptive and antipyretic activities of clove oil in mice. Libyan J. Med., 10(1):285-286.

Tanko, Y.; Mohammed, A.; Okasha, M. A.; Umah, A. and Magaji, R. (2008). Antinociceptive and anti-inflammatory activities of ethanol extract of Syzygium aromaticum flower bud in wistar rats and mice. Afr. J. Tradit. Complement. Altern. Med., 5(2):209-212.

Tijjani, R.; Zezi, A.; Shafiu, R. and Umar, M. (2015). Anti-inflammatory and antioxidants properties of the ethanolic stem bark extract of Cordia africana (Lam.). Ann. Phytomed., 4(2):83-87.

Winter, C. A.; Risley, E. A. and Nuss, G. W. (1962). Carrageenin-induced edema in hind paw of the rat as an assay for antiinflammatory drugs. Proc. Soc. Exp. Biol. Med., 111(3):544-547.

Citation: Brijesh R. Humbal, Kamlesh A. Sadariya, Jaimin A. Prajapati, Shailesh K. Bhavsar and Aswin M. Thaker (2019). Anti-inflammatory activity of Syzygium aromaticum (L.) Merrill \& Perry oil in carrageenan-induced paw edema in female rats. Ann. Phytomed., 8(2):167-171. 